\title{
Exenatide can inhibit calcification of human VSMCs through the NF-kappaB/RANKL signaling pathway
}

\author{
Jun-Kun Zhan, Pan Tan, Yan-Jiao Wang, Yi Wang, Jie-Yu He, Zhi-Yong Tang, Wu Huang and You-Shuo Liu*
}

\begin{abstract}
Background: Arterial calcification is an important pathological change of diabetic vascular complication. Osteoblastic differentiation of vascular smooth muscle cells (VSMCS) plays an important cytopathologic role in arterial calcification. The glucagon-like peptide-1 receptor agonists (GLP-1RA), a novel type of antidiabetic drugs, exert cardioprotective effects through the GLP-1 receptor (GLP-1R). However, the question of whether or not GLP-1RA regulates osteoblastic differentiation and calcification of VSMCs has not been answered, and the associated molecular mechanisms have not been examined.
\end{abstract}

Methods: Calcifying VSMCs (CVSMCs) were isolated from cultured human arterial smooth muscle cells through limiting dilution and cloning. The extent of matrix mineralization was measured by Alizarin Red S staining. Protein expression and phosphorylation were detected by Western blot. Gene expression of receptor activator of nuclear factor-kB ligand (RANKL) was silenced by small interference RNA (siRNA).

Results: Exenatide, an agonist of GLP-1 receptor, attenuated $\beta$-glycerol phosphate ( $\beta$-GP) induced osteoblastic differentiation and calcification of human CVSMCs in a dose- and time-dependent manner. RANKL siRNA also inhibited osteoblastic differentiation and calcification. Exenatide decreased the expression of RANKL in a dose-dependent manner. 1,25 vitD 3 (an activator of RANKL) upregulated, whereas BAY11-7082 (an inhibitor of NF-KB) downregulated RANKL, alkaline phosphatase (ALP), osteocalcin (OC), and core binding factor a1 (Runx2) protein levels and reduced mineralization in human CVSMCs. Exenatide decreased p-NF-KB and increased p-AMPKa levels in human CVSMCs $48 \mathrm{~h}$ after treatment. Significant decrease in p-NF-KB (p-Ser ${ }^{276}, \mathrm{p}-\mathrm{Ser}^{536}$ ) level was observed in cells treated with exenatide or exenatide + BAY11-7082.

Conclusion: GLP-1RA exenatide can inhibit human VSMCs calcification through NF-KB/RANKL signaling.

Keywords: Arterial calcification, Vascular smooth muscle cells, Osteoblastic differentiation, Glucagon-like peptide-1, Diabetes

\section{Introduction}

Diabetes mellitus is a major risk factor for the development of cardiovascular disease [1]. Currently, treatment of diabetes and its cardiovascular complications with classic drugs is effective in less than $50 \%$ of patients [2]. Novel therapies are therefore required to manage diabetes mellitus and mitigate cardiovascular risks. GLP-1 is an incretin hormone that is rapidly released from intestinal L-cells after food intake. GLP-1 has insulinotropic effects, and it lowers blood glucose in a glucose-dependent manner [3]. Targeting of glucagon-like peptide-1 receptor (GLP-1R)

\footnotetext{
* Correspondence: Liuyoushuo@yeah.net

Department of Geriatrics, Institute of Aging and Geriatrics, The Second Xiangya Hospital, Central South University, 139 Middle Renmin Road, Changsha, Hunan 410011, P.R. China
}

has been developed to complement conventional treatment options for diabetes mellitus. This class of drugs is currently undergoing clinical trials for the treatment of type 2 diabetes.

Exenatide is a synthetic peptide sharing $53 \%$ sequence homology with GLP-1 and has been used as an agonist of mammalian GLP-1 receptor (GLP-1RA) for the treatment of type 2 diabetes $[4,5]$. In clinical trials, treatment with exenatide once a week assisted more patients in reaching the majority of ADA-recommended therapeutic goals than treatments with other drugs, such as sitagliptin, pioglitazone, or insulin glargine [6]. However, the residual adverse effect of sulphonylurea was also higher in patients who were treated with exenatide once a week 
[7]. Compared to conventional treatments, GLP-1RAs not only have an advantage in lowering blood sugar, but also have other benefits. For example, it has been reported that exenatide confers cardioprotection $[4,5,8]$. Arterial calcification is an important pathological change of diabetic vascular complication, which results in cardiovascular events and amputations [9]. However, the question of whether or not GLP-1RA regulates arterial calcification has not been answered, and the associated molecular mechanisms have not been examined.

Studies have suggested that arterial calcification is an active and tightly regulated process similar to bone formation $[10,11]$. The differentiation of vascular smooth muscle cell (VSMC) to an osteoblastic phenotype is a key component of the cytopathologic foundation of arterial calcification [12-15]. Calcifying VSMCs (CVSMCs) can spontaneously form calcification nodules and express osteoblast phenotype genes, such as ALP, OC, and Runx2 $[16,17]$, which are often used together as a cell model in arterial calcification research [18]. Receptor activator of nuclear factor- $\mathrm{kB}$ ligand (RANKL) is a member of the tumor necrosis factor family and is important for bone remodeling [19]. Researchers have discoved that OPGdeficient mice develop severe osteoporosis and arterial calcification [20,21]. OPG inhibits nuclear kappa B (NF-kB) by binding RANKL. RANKL directly promotes calcification of VSMCs [22]. In addition, elevated serum OPG has been observed to be associated with vascular calcification in humans with T2DM [23]. The elevated serum OPG may interfere with RANK/RANKL interactions in the vascular wall. In cardiovascular diseases, RANKL is positively associated with circulating OPG [24].

In the present study, we investigated the effects of exenatide and RANKL in the osteoblastic differentiation and calcification of CVSMCs and examined the associated mechanisms.

\section{Materials and methods}

\section{Cell culture and in vitro calcification}

Human VSMCs were isolated from excess donor vasculature after kidney transplantations as previously described [25]. Briefly, the arterial tissues were removed and rinsed several times in Hanks's balanced salt solution. The arterial tissues were then minced and digested in $5 \mathrm{ml}$ of digestion solution $(0.25 \mathrm{mg} / \mathrm{ml}$ soybean trypsin inhibitor, $0.125 \mathrm{mg} / \mathrm{ml}$ elastase, $2.0 \mathrm{mg} / \mathrm{ml}$ crystallized bovine albumin, $10 \mathrm{mg} / \mathrm{ml}$ collagenase I, and $15 \mathrm{mM} \mathrm{HEPES}$ ) at $37^{\circ} \mathrm{C}$ for $45 \mathrm{~min}$. The digested cells were filtered through a sterile 100-mM nylon mesh, centrifuged at 1,000 rpm for $10 \mathrm{~min}$, and washed with Dulbecco's modified Eagle's medium (DMEM) containing high glucose concentration (4500 mg/L) and 10\% FBS (Gibco-BRL). CVSMCs were isolated from cultured VSMCs when multicellular nodules spontaneously appeared. Briefly, cells were cloned by limiting dilution. Colonial cells were identified as CVSMCs by positive $\alpha$-actin staining and by high ALP expression and formation of calcified nodules. This study was approved by the Ethics Review Board of Second Xiangya Hospital, Central South University. Written informed consent was obtained from patients.

\section{Mineralization assay}

The extent of matrix mineralization in cultured CVSMCs was determined by Alizarin Red S staining. Briefly, cells were fixed with $4 \%$ formaldehyde for $10 \mathrm{~min}$ at room temperature and exposed to 2\% Alizarin Red S for $5 \mathrm{~min}$. Cells were then washed with PBS to remove excess dye. For quantitative analysis of Alizarin Red S staining, the dye was released from the cell matrix by incubating with cetyl-pyridinium chloride for $15 \mathrm{~min}$. The amount of released dye was quantified by spectrophotometry at $540 \mathrm{~nm}$. Results were normalized to the total amount of cellular proteins.

\section{Osteoblastic differentiation}

Human CVSMCs were fixed in 4\% paraformaldehyde, washed with Tris-Tween-20 buffer, and permeabilized for $20 \mathrm{~min}$ in buffer containing $0.1 \%$ triton-X. After blocking for $1 \mathrm{~h}$, cells were incubated with primary antibodies overnight at $4^{\circ} \mathrm{C}$, followed by secondary antibodies for $30 \mathrm{~min}$. anti-ALP, anti-Runx2, and anti-OC primary antibodies and secondary antibodies were purchased from Santa Cruz Biotechnology (Santa Cruz, CA, USA).

To analyze the dose dependence of calcification on exenatide, CVSMCs were cultured with $\beta$-GP $(10 \mathrm{mM})$ and $0,100 \mathrm{pM}, 1 \mathrm{nM}$, and $100 \mathrm{nM}$ of exenatide in serumfree high glucose DMEM for $48 \mathrm{hrs}$. ALP activity was determined using the spectrophotometric measurement of p-nitrophenol level in the culture medium [26]. Osteocalcin level was measured using a radioimmunoassay kit (DiaSorin, Stillwater, MN, USA). The ALP activity and OC level were then normalized to the total amount of cellular protein.

\section{Silencing of RANKL by RNA interference}

Three RANKL target sequences (S1: 5'-GTGCAGAAAT GGCGAGAATAC-3', S2: 5'-GGAUGGCUCAUGGUUA GAUTT-3', S3: 5'-CGGAUCAGGAUGCAACAUATT-3') were used to design and synthesize siRNA. A scrambled siRNA sequence was used as a control for siRNA transfection as previously described [27]. CVSMCs were plated onto $60-\mathrm{mm}$ dishes and cultured in DMEM without antibiotics 24 hours before siRNA transformation. Cells were transfected with RANKL siRNA or control siRNA using Lipofectamine 2000 (Invitrogen, Grand Island, NY) according to the instructions of the manufacturer and continually cultured for 72 hours. Cells were then harvested for analyses of RANKL expression. Among the 3 
siRNAs, siRNA derived from the $\mathrm{S} 2$ target sequence was the most effective in silencing RANKL expression and was used for further experiments in this study.

\section{Western blot}

Protein concentration was measured using a BCA Protein Assay kit (Beyotime, Shanghai, China). 20- $\mu$ g of total protein was loaded onto a 12\% SDS-PAGE gel and transferred onto nitrocellulose membranes. After blocking with 5\% non-fat milk for $1 \mathrm{~h}$, membranes were incubated with primary antibody overnight at $4^{\circ} \mathrm{C}$ and subsequently incubated with HRP-labeled secondary antibody (1:2000 dilution) for $2 \mathrm{~h}$ at room temperature. Reactive proteins were detected using chemiluminescent reagents (Pierce, Rockford, IL, USA). To control for loading efficiency, the blots were stripped and reprobed with GAPDH (glyceraldehyde-3-phosphatedehydrogenase) antibody. Primary antibodies for RANKL, AMPK $\alpha$, Phospho-AMPK $\alpha$ $\mathrm{Thr}^{172}$, ERK1/2, Phospho-ERK, JNK, Phospho-JNK, NF-кB p65, phospho-NF-kB (p-NF-kB Ser ${ }^{276}$, p-NF-kB Ser ${ }^{529}$ and p-NF-kB Ser ${ }^{536}$ ), and GAPDH were purchased from Santa Cruz Biotechnology (Santa Cruz, CA, USA).

\section{Statistical analysis}

Data were presented as mean \pm standard deviation (SD) and analyzed using Statistical Product and Service Solutions (SPSS, version 17.0). Differences between two groups were analyzed using Student's t-test. $\mathrm{P}<0.05$ was considered statistically significant.

\section{Results}

Effects of exenatide and RANKL-siRNA on osteoblastic differentiation and calcification of human CVSMCs

To determine the effect of GLP-1RA and RANKL on the osteoblastic differentiation and calcification of human CVSMCs, a GLP-1 receptor agonist (exenatide) and RANKL siRNA were used. Figure $1 \mathrm{~A}$ shows that RNA interference efficiently knocked down RANKL gene expression in human CVSMCs. Treatment with siRNARANKL blocked the expression of RANKL protein in human CVSMCs. Further examination found that exenatide inhibited ALP activity (Figure 1B) and OC secretion (Figure 1C) in $\beta$-GP-treated VSMCs in a dose-dependent manner. Two nM of exenatide was selected for further studies. Two nM of exenatide downregulated ALP protein level in human CVSMCs compared to cells without exenatide treatment (Figure 1D and E). Moreover, treatment of human CVSMCs with exenatide + RANKL-siRNA or RANKL-siRNA alone downregulated ALP and RANKL protein levels (Figure 1D and E). Alizarin Red S staining showed weaker staining in CVSMCs treated with exenatide + RANKL-siRNA compared to control cells or cells treated with exenatide or RANKL-siRNA alone (Figure 1 $\mathrm{F}$ and $\mathrm{G}$ ). These results indicated that exenatide treatment and RANKL siRNA attenuated the osteoblastic differentiation and calcification of human CVSMCs.

Dose-effect relationship of the regulation of RANKL expression by exenatide in human CVSMCs and possible signaling pathways

Recent studies have demonstrated that several signaling pathways regulate RANKL expression in osteoblasts or VSMCs, such as AMPK, JNK, ERK1/2 and NF-kB signaling $[11,28,29]$. As shown in Figure 2A, exenatide decreased the expression of RANKL in a dose-dependent manner. Also, exenatide decreased $\mathrm{p}-\mathrm{NF}-\mathrm{kB}$ and increased p-AMPK $\alpha$ levels in human CVSMCs $48 \mathrm{~h}$ after treatment. In contrast, exenatide did not affect the protein level of AMPK $\alpha$, ERK1/2, p-ERK1/2, JNK, p-JNK, or NF-kB (Figure 2).

\section{Effects of NF-KB inhibitor and RANKL activator on exenatide-inhibited osteoblastic differentiation and calcification of human CVSMCs}

Human CVSMCs were treated with or without exenatide (2 nM), BAY11-7082 (an inhibitor of NF-kB, $10 \mu \mathrm{M}$ ), and 1,25-dihydroxyvitamin D3 (1,25vitD3) (an activator of RANKL, $10^{-7} \mathrm{M}$ ) [30] for $48 \mathrm{~h}$. The expression of ALP, OC, and Runx 2 proteins was detected by Western blot. Results showed that $2 \mathrm{nM}$ of exenatide downregulated ALP, OC, and Runx2 protein levels in human CVSMCs compared to cells without exenatide treatment (Figure 3A and $3 \mathrm{~B}$ ). 1,25vitD 3 upregulated ALP, OC, and Runx2 protein levels in human CVSMCs compared to cells treated with exenatide alone. Treatment of human CVSMCs with $2 \mathrm{nM}$ of exenatide and $10 \mu \mathrm{M}$ of BAY11-7082 more effectively downregulated ALP, OC, and Runx2 protein levels compared to cells treated with $2 \mathrm{nM}$ of exenatide, 1,25 vitD $\mathrm{D}_{3}$, or cells without treatment. Weaker Alizarin Red S staining was observed in CVSMCs cultured with exenatide alone than in cells cultured without exenatide. Stronger Alizarin Red S staining was observed in human CVSMCs cultured with exenatide and 1,25 vitD $_{3}$ than in cells cultured with exenatide alone or exenatide + BAY11-7082 (Figure $3 \mathrm{C}$ and $\mathrm{D}$ ). These results suggested that exenatide treatment may attenuate osteoblastic differentiation and calcification of human CVSMCs through NF- $\mathrm{kB}$ signaling. RANKL activation exhibits the opposite effect.

\section{Roles of RANKL and phosphorylation of NF-KB in exenatide-inhibited osteoblastic differentiation and calcification of human CVSMCs}

We further investigated RANKL, NF- $\mathrm{kB}$ and $\mathrm{p}-\mathrm{NF}-\mathrm{kB}$ $\left(\mathrm{p}-\mathrm{Ser}^{529}, \mathrm{p}-\mathrm{Ser}^{276}, \mathrm{p}-\mathrm{Ser}^{536}\right.$ ) protein levels in human CVSMCs treated with or without exenatide (2 nM), BAY11-7082 $(10 \mu \mathrm{M})$, and 1,25 vitD3 $\left(10^{-7} \mathrm{M}\right)$ (Figure 4A). The protein level of RANKL was significantly decreased in cells treated with exenatide alone compared to cells 

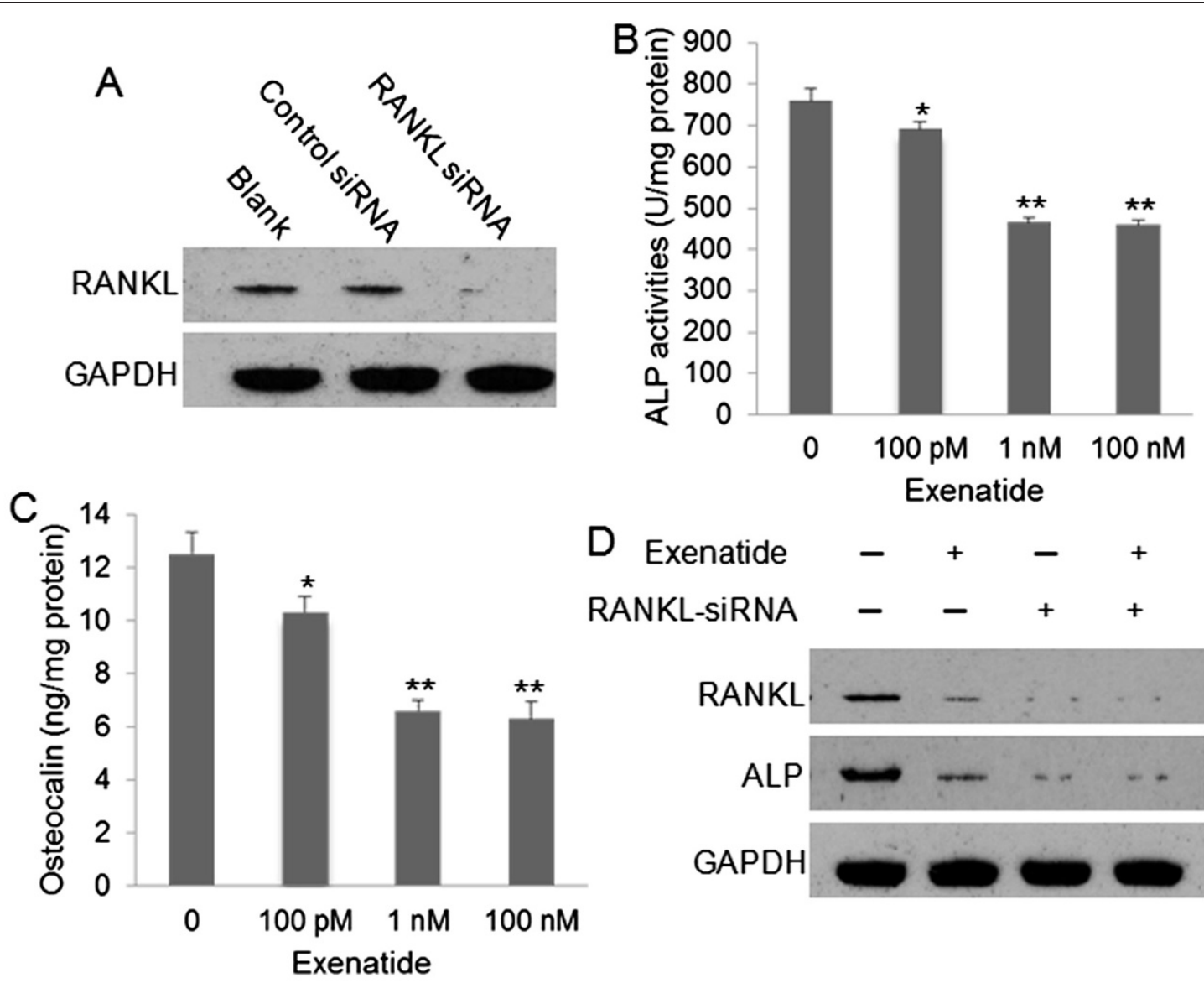

$\begin{array}{lllll}\text { D Exenatide } & - & + & - & + \\ \text { RANKL-siRNA } & - & - & + & +\end{array}$
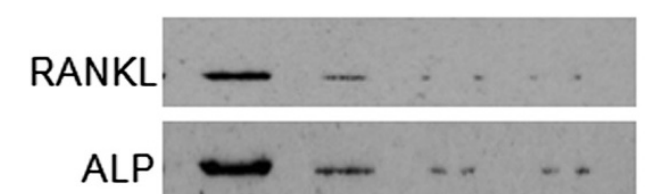

GAPDH

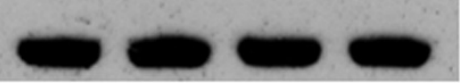

Exenatide
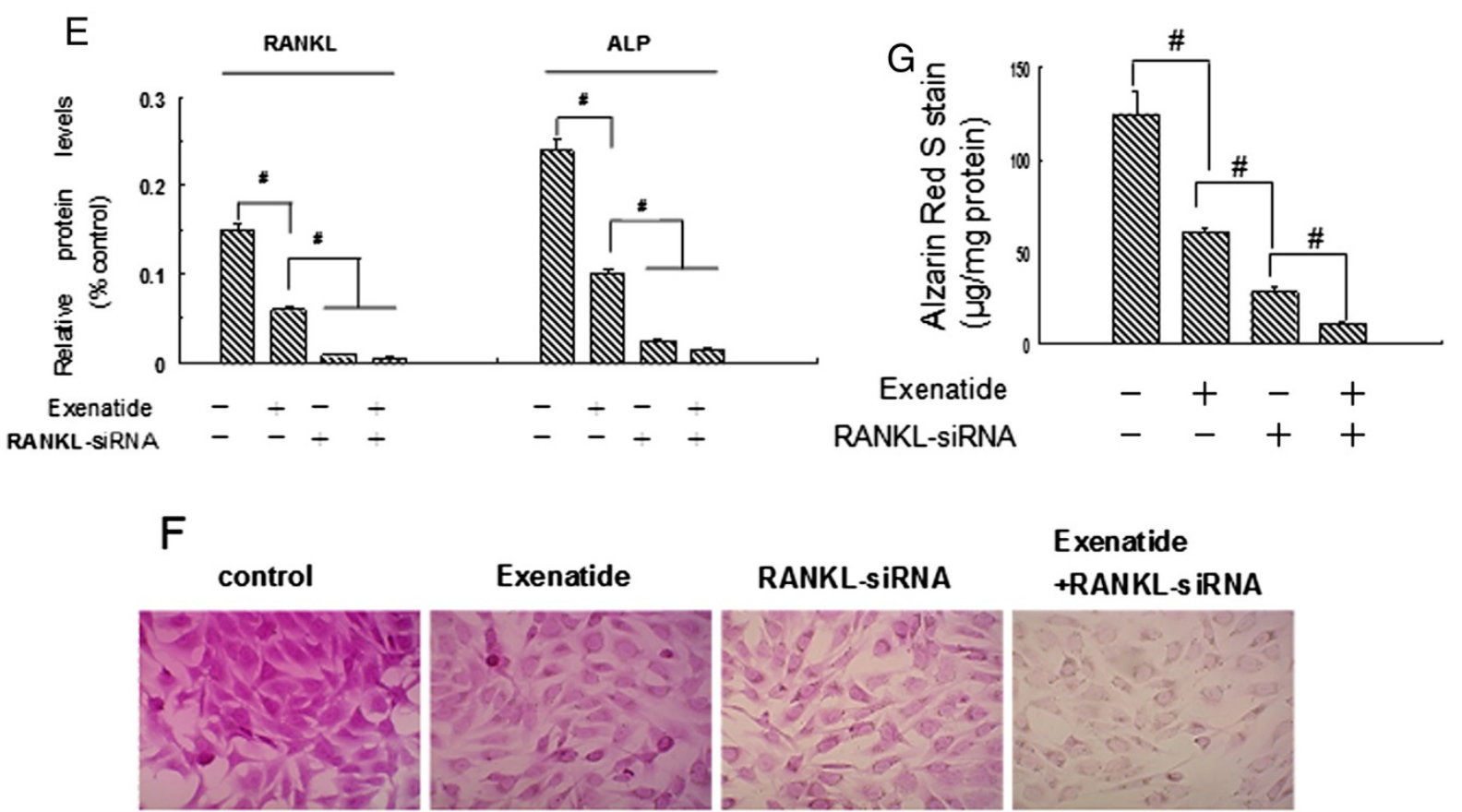

Exenatide

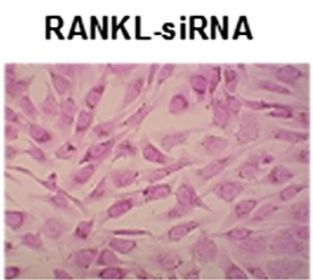

Exenatide

+RANKL-s IRNA
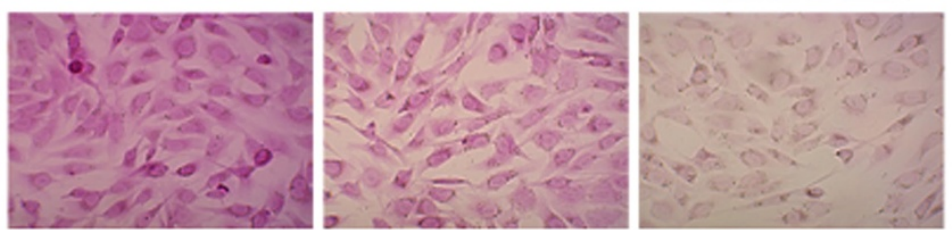

Figure 1 (See legend on next page.) 
(See figure on previous page.)

Figure 1 Exenatide and RANKL-siRNA attenuate osteoblastic differentiation and calcification of human CVSMCs. A) Representative Western blot of RANKL protein levels in human CVSMCs transfected with control siRNA (C-siRNA) or R-siRNA for 48 hours. B) Exenatide inhibited ALP activities in $\beta$-GP-treated VSMCs in a dose-dependent manner. VSMCs were treated for 48 hrs. $N=5,{ }^{* *} \mathrm{P}<0.001$ vs. control $(0$ concentration of exenatide). C) Exenatide inhibited OC levels in $\beta$-GP-treated VSMCs in a dose-dependent manner. VSMCs were treated for 48 hrs. $N=5$, ${ }^{* * *} P<0.001$ vs. 0 concentration of exenatide. D) Representative Western blot of ALP and RANKL protein expressions. Human CVSMCS were treated with or without exenatide ( $2 \mathrm{nM}$ ) and RANKL-siRNA (R-siRNA) for $48 \mathrm{~h}$. GAPDH was used as the loading control. E) Semi-quantitative analysis of bands in Western blot at 48 hrs in each group. Bars represent mean \pm SD. ${ }^{\#} P<0.001$ between two indicated groups. $N=5$. F) Representative Alizarin Red $S$ staining. Human CVSMCs were treated with various agents for 15 days. Magnification $\times 200$. G) Quantification of Alizarin red S staining. The dye was extracted and quantified as described in the Method section. Bars represent mean $\pm \mathrm{SD}$. ${ }^{\#} \mathrm{P}<0.001$ between two indicated groups. $\mathrm{N}=5$.

\section{A}

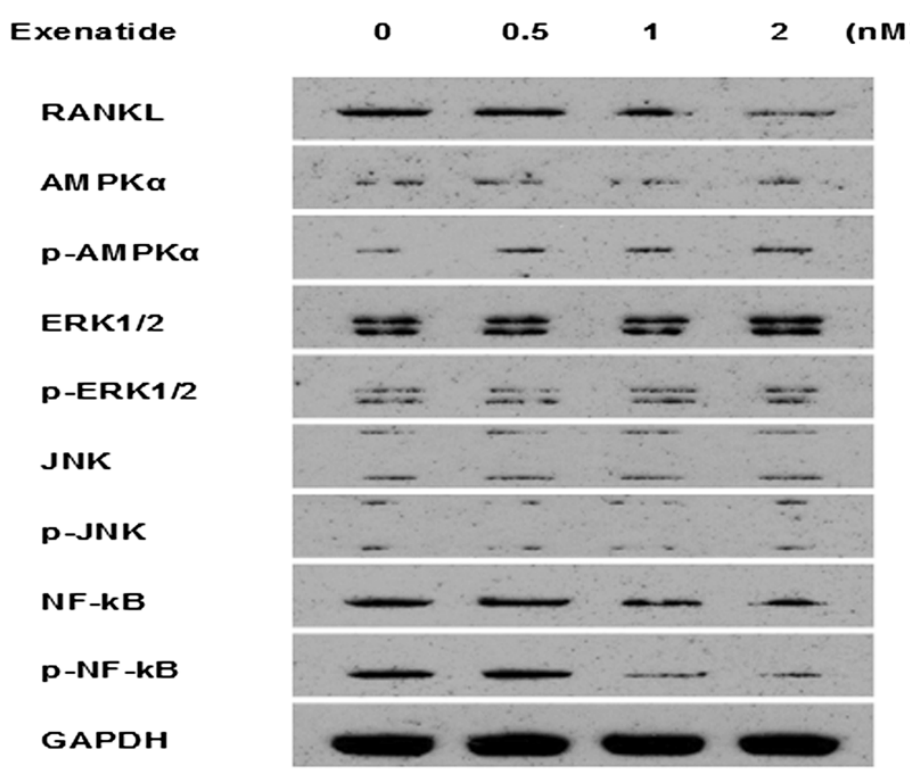

B

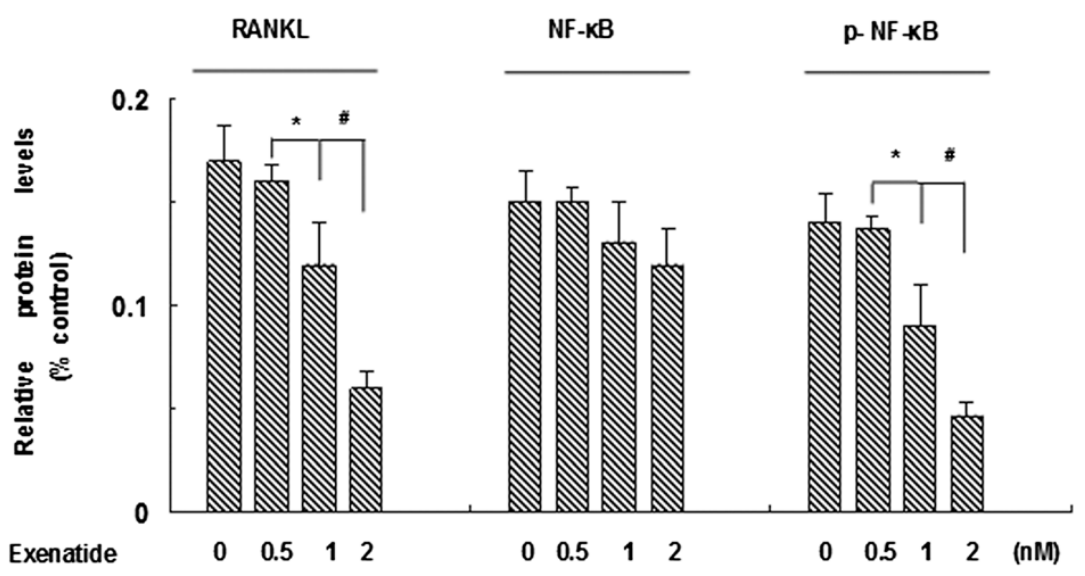

Figure 2 Exenatide-inhibited osteoblastic differentiation and calcification of human CVSMCs requires NF-KB. A) Human CVSMCS were treated with different concentrations of exenatide for 48 hrs. Representative Western blot of RANKL, AMPKa, p-AMPKa, ERK1/2, p- ERK1/2, JNK, $\mathrm{p}-J N K, N F-K B, p-N F-K B$ protein expression. B) Semi-quantitative analysis of bands in Western blot. GAPDH was used as the loading control. Bars represent mean $\pm S D .{ }^{*} P<0.01$ and ${ }^{\#} P<0.001$ between two indicated groups. $N=5$. 


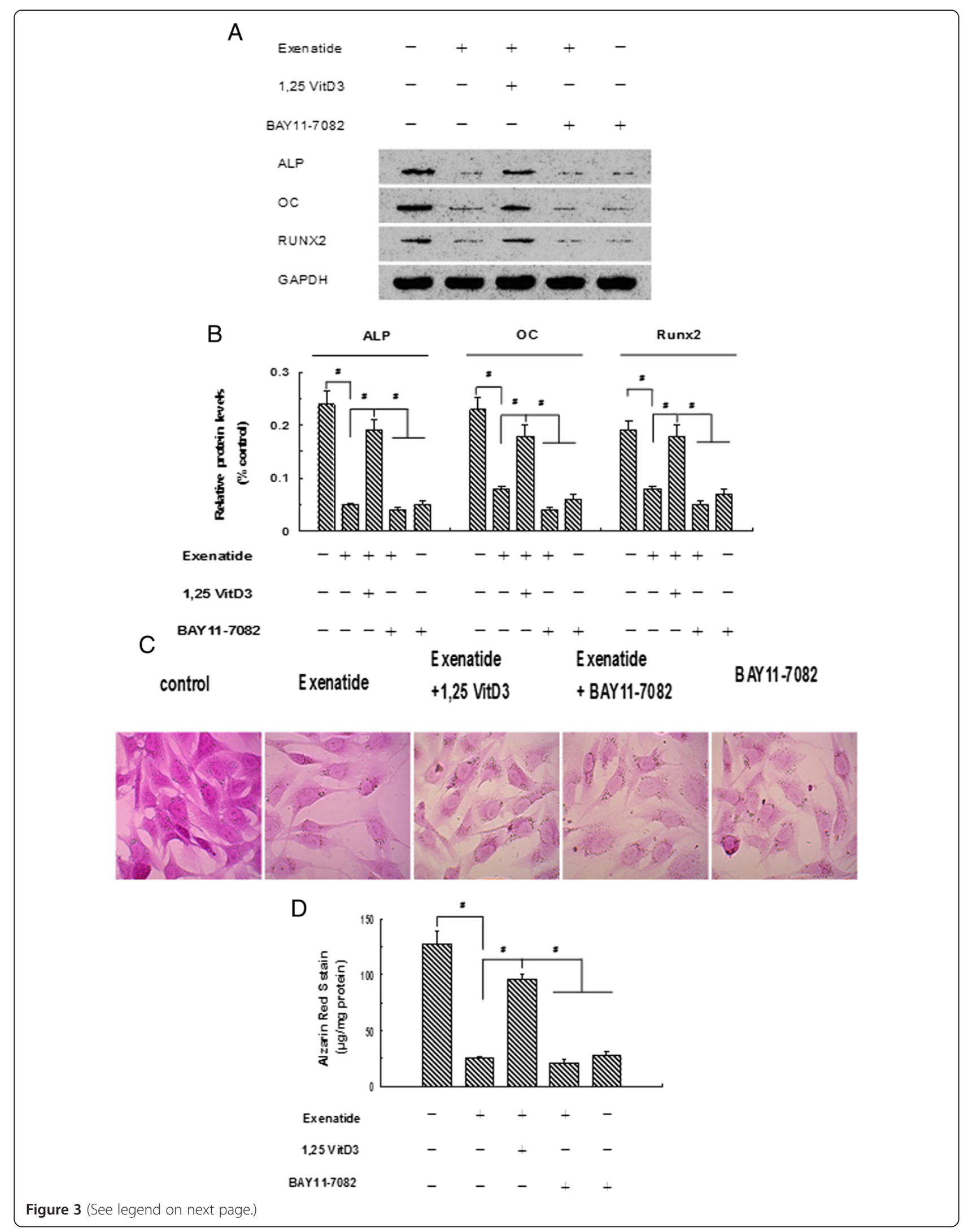


(See figure on previous page.)

Figure 3 Exenatide-inhibited osteoblastic differentiation and calcification of human CVSMCs can be regulated by NF-KB inhibitor and

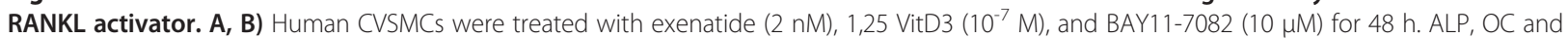
Runx2 protein expressions were detected by Western blot. GAPDH was used as the loading control Bars represent mean \pm SD. ${ }^{\# P}<0.001$ between two indicated groups. $N=5$. C) Human CVSMCs were treated with various agents for 15 days. The calcification was visualized by Alizarin Red $S$ staining. Magnification $\times 200$. D) Quantification of Alizarin red S staining. The dye was extracted and quantified as described in the Method section. Bars represent mean \pm SD. ${ }^{\#} P<0.001$ between two indicated groups. $N=5$.

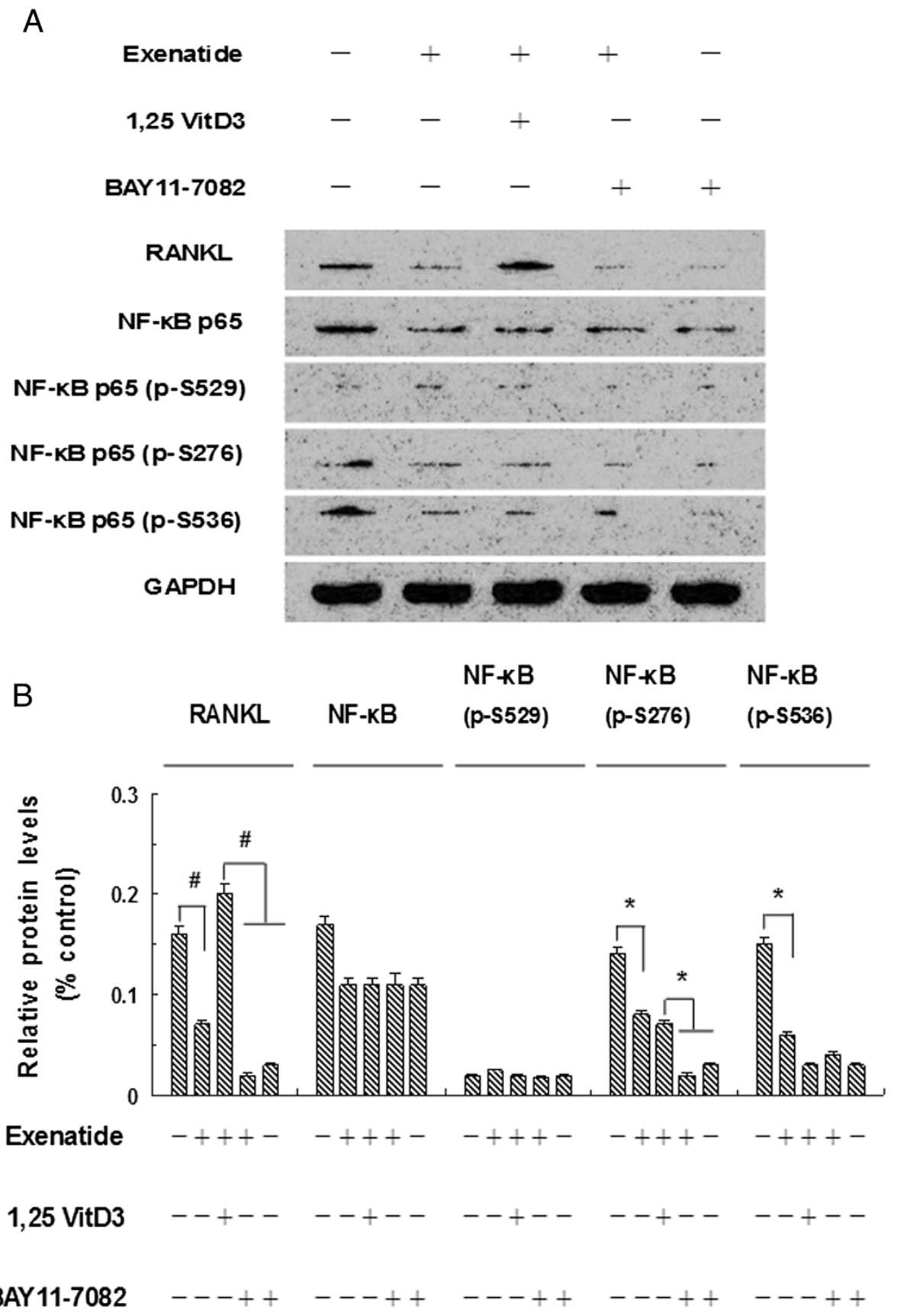

Figure 4 The effect of exenatide in the phosphorylation of NF-KB and the expression of RANKL in human CVSMCs. A) Human CVSMCS were treated with exenatide $(2 \mathrm{nM}), 1,25 \mathrm{VitD} 3\left(10^{-7} \mathrm{M}\right)$ and BAY11-7082 $(10 \mu \mathrm{M})$ for $48 \mathrm{~h}$. RANKL, NF-kB, p-NF-kB (S529, S276, S536) levels were detected by Western blot. GAPDH was used as the loading control. B) These results were reported at $48 \mathrm{~h}$ in each group. Bars represent mean \pm SD. ${ }^{*} \mathrm{P}<0.01$ and ${ }^{\#} \mathrm{P}<0.001$ between two indicated groups. $\mathrm{N}=5$. 
without exenatide treatment. Pretreatment of cells with the NF- $\mathrm{KB}$ inhibitor BAY11-7082 downregulated the protein level of RANKL. Conversely, pretreatment of cells with the RANKL activator 1,25 vitD $_{3}$ upregulated the protein level of RANKL. These results indicated that RANKL is a downstream mediator for exenatidereduced osteoblastic differentiation and calcification of CVSMCs. Western blot showed a significant decrease in $\mathrm{p}-\mathrm{NF}-\mathrm{kB}\left(\mathrm{p}-\mathrm{Ser}^{276}, \mathrm{p}-\mathrm{Ser}^{536}\right)$ level in cells treated with exenatide or exenatide + BAY11-7082 compared to cells in the no treatment group (Figure 4A and $4 \mathrm{~B}$ ). No changes in total NF- $\mathrm{kB}$ or NF- $\mathrm{kB}$ p65 $\left(\mathrm{p}-\mathrm{Ser}^{529}\right)$ levels were observed in human CVSMCs with different treatments. These results indicated that suppression of NF- $\mathrm{kB}$ phosphorylation, but not its expression, is necessary for exenatide-inhibited osteoblastic differentiation and calcification in human CVSMCs.

\section{Discussion}

Type 2 diabetes mellitus is a progressive disease characterized by persistent insulin resistance and declining pancreatic $\beta$-cell function [31]. However, long-term glycemic control is hard to achieve because of deteriorating $\beta$-cell function. A multicentre randomized parallel-group trial suggested that exenatide was more effective in improving $\beta$-cell function compared to insulin and piogltazone; hence, early initiation of $\beta$-cell-protective therapy with exenatide may halt the decline in $\beta$-cell function in type 2 diabetes [32]. Indeed, two years after treatment initiation, patients on exenatide twice a day showed a significant reduction in body mass index and hemoglobin A1c compared with patients treated with a longacting insulin analog [33]. In addition, even after only three months, exenatide therapy exhibited similar effects on microvascular endothelial function, inflammation markers, oxidative stress, and vascular activation as metformin in patients with obesity and pre-diabetes [34]. In this study, exenatide was able to inhibit human VSMCs calcification in cells cultured with high glucose concentration, suggesting that exenatide may exert its effect dependent on glucose concentration. Therefore, the detected alterations may play a role in the prevention of diabetes-induced vascular calcification.

Recent studies have suggested that GLP-1RA exhibits potential cardioprotective properties in addition to its role in lowering glucose level [35]. In animal models, exenatide has been demonstrated to be capable of protecting the heart against ischemia/reperfusion injury $[4,36]$, reducing infarct size, improving cardiac function [4], and retarding atherosclerotic lesion formation [37]. Bao et al study demonstrated that sustained GLP-1 receptor activation plays an important role in providing cardioprotection in the setting of acute myocardial I/R injury [38]. However, the question of whether or not GLP-1RA protects the cardiovascular system by regulating VSMCs osteoblastic differentiation and calcification has not been answered, and the associated molecular mechanism is still unclear. Expression of ALP, OC, and Runx2 is a marker of osteoblastic differentiation, while matrix mineralization is a hallmark of the osteoblast phenotype $[14,15]$. In this study, we demonstrated that exenatide downregulated the expression of ALP, OC, and Runx2. In addition, exenatide inhibited mineralized nodule formation. We show for the first time that the GLP-1RA exenatide can inhibit osteoblastic differentiation and calcification of human CVSMCs.

Overexpression of RANKL has been found to stimulate VSMC mineralization [19-22,39]. However, most of the evidence for the direct role of RANKL signaling in arterial calcification is derived from animal studies. Little data is available on the role of RANKL signaling in relation to arterial calcification in human cells. The present study showed that exenatide inhibited RANKL expression in human CVSMCs through the NF-kB pathway and mitigated CVSMCs calcification. These findings suggest that exenatide inhibits the calcification of human CVSMCs via the NF-kB/RANKL signaling pathway.

The RANKL complex, consisting of the membranebound RANK, its ligand RANKL, and the decoy receptor OPG, is thought to be important for bone metabolism. Osteoblasts express OPG and RANKL, which regulate osteoclast differentiation through the activation of RANK [40]. The present study showed that exenatide could decrease the expression of RANKL and inhibit the expression of ALP, OC, and Runx2 in human CVSMCs. Furthermore, inhibition of RANKL expression by siRNA abrogated the role of exenatide in ALP expression in human CVSMCs. These findings suggest that RANKL is a key mediator in exenatide-induced inhibition of osteoblastic differentiation of human CVSMCs.

The NF- $\mathrm{kB}, \mathrm{MAPK}, \mathrm{ERK}$, and NFAT signaling pathways have been demonstrated to regulate RANKL expression in osteoblast cells $[29,41]$ and VSMCs [11,28]. In this study, exenatide inhibited the activation of NF- $\mathrm{kB}$ in human CVSMCs. Pretreatment of cells with NF- $\mathrm{kB}$ inhibitor inhibited the expression of RANKL in human CVSMCs. The NF- $\mathrm{kB}$ inhibitor BAY11-7082 abolished the effect of RANKL activator $\left(1,25\right.$ vitD $\left._{3}\right)$ - promoted RANKL expression. In contrast, no changes in AMPK $\alpha$, ERK1/ 2, p-ERK1/2, JNK, and p-JNK protein level have been observed in this study.

The NF- $\mathrm{BB}$ family consists of five members, RelA (p65), RelB, NF-кB1 (p50), NF-кB2 (p52), and c-Rel. p65 heterodimer is the predominant form in most cell types. The activation of NF- $\mathrm{kB}$ p65 is mediated by phosphorylation at $\operatorname{Ser}^{529}, \operatorname{Ser}^{536}$ and $\mathrm{Ser}^{276}$ residues [42]. However, the different functions of phosphorylation at these residues in arterial calcification have not been identified. In 
this study, we revealed that blocking NF-kB p65 phosphorylation at $\operatorname{Ser}^{536}$ and $\operatorname{Ser}^{276}$, but not at $\operatorname{Ser}^{529}$, abolishes NF- $\mathrm{kB}$ p65 activity. These findings provide direct evidence that phosphorylation of NF- $\mathrm{KB}$ p 65 at $\mathrm{Ser}^{536}$ and $\mathrm{Ser}^{276}$ is required for $\beta$-GP-induced NF-kB activation in the osteoblastic differentiation of human CVSMCs.

\section{Conclusion}

In conclusion, GLP-1RA exenatide can inhibit osteoblastic differentiation and calcification of human CVSMCs through the NF-kB/RANKL signaling pathway. This finding may represent a new therapeutic potential in arterial calcification for GLP-1RA, which is currently undergoing clinical trials for the treatment of type 2 diabetes.

\begin{abstract}
Abbreviations
$\beta$-GP: $\beta$-glycerol phosphate; ALP: Alkaline phosphatase; OC: Osteocalcin; Runx2: Core binding factor a1; VSMCs: Vascular smooth muscle cells; CVSMCs: Calcifying vascular smooth muscle cells; NF-kB: Nuclear Factor KB; RANKL: Receptor activator of nuclear factor-KB ligand; GLP-1RA: Glucagon-like peptide-1 receptor agonists; GLP-1R: Glucagon-like peptide-1 receptor; CVSMCs: Calcifying vascular smooth muscle cells; SPSS: Statistical package for the social science; siRNA: Small interference RNA; MAPK: Mitogen-activated protein kinase; AMPK: AMP-activated protein kinase; JNK: c-Jun N-terminal kinase; OPG: Osteoprotegerin; ERK: Extracellular signal-regulated kinase; RANK: Nuclear factor $\mathrm{KB}$ receptor activator; NEAT: Nuclear factor of activated T-cells.
\end{abstract}

\section{Competing interests}

All authors declared that they have no competing interests.

\section{Authors' contributions}

JKZ, PT, YJW, and YW carried out the molecular and cellular studies. JKZ and PT participated in the drafted the manuscript. JYH, ZYT, and WH participated in the graph preparation and the statistical analysis. YSL conceived of the study, and participated in its design and coordination and helped to draft the manuscript. All authors read and approved the final manuscript.

\section{Acknowledgments}

This study was supported by the National Natural Science Foundation of China (No.81370931), the National Basic Research Program of China (No. 2014CB910500), the Hunan Provincial Natural Science Foundation of China (No. 13JJ3023), and Hunan Provincial Science and Technology Program (No.2014FJ6065)

Received: 21 July 2014 Accepted: 29 October 2014

Published online: 19 November 2014

\section{References}

1. Sarwar N, Gao P, Seshasai SR, Gobin R, Kaptoge S, Di Angelantonio E, Ingelsson E, Lawlor DA, Selvin E, Stampfer M, Stehouwer CD, Lewington S, Pennells L, Thompson A, Sattar N, White IR, Ray KK, Danesh J: Diabetes mellitus, fasting blood glucose concentration, and risk of vascular disease: a collaborative meta-analysis of 102 prospective studies. Lancet 2010, 375:2215-2222.

2. Saydah SH, Fradkin J, Cowie CC: Poor control of risk factors for vascular disease among adults with previously diagnosed diabetes. JAMA 2004, 291:335-342.

3. Lee YS, Jun HS: Anti-diabetic actions of glucagon-like peptide-1 on pancreatic beta-cells. Metabolism 2014, 63:9-19.

4. Timmers L, Henriques JP, de Kleijn DP, Devries JH, Kemperman H, Steendijk P, Verlaan CW, Kerver M, Piek JJ, Doevendans PA, Pasterkamp G, Hoefer IE: Exenatide reduces infarct size and improves cardiac function in a porcine model of ischemia and reperfusion injury. J Am Coll Cardiol 2009, 53:501-510
5. Drucker DJ, Nauck MA: The incretin system: glucagon-like peptide-1 receptor agonists and dipeptidyl peptidase-4 inhibitors in type 2 diabetes. Lancet 2006, 368:1696-1705.

6. Meloni AR, DeYoung MB, Han J, Best JH, Grimm M: Treatment of patients with type 2 diabetes with exenatide once weekly versus oral glucose-lowering medications or insulin glargine: achievement of glycemic and cardiovascular goals. Cardiovasc Diabetol 2013, 12:48.

7. Paul SK, Maggs D, Klein K, Best JH: Dynamic risk factors associated with non-severe hypoglycaemia in patients treated with insulin glargine or exenatide once weekly. J Diabetes 2014, doi: 10.1111/1753-0407.12208.

8. Mafong DD, Henry RR: Exenatide as a treatment for diabetes and obesity: implications for cardiovascular risk reduction. Curr Atheroscler Rep 2008, 10:55-60.

9. Brechow A, Slesaczeck T, Münch D, Nanning T, Paetzold H, Schwanebeck U, Bornstein S, Weck M: Improving major amputation rates in the multicomplex diabetic foot patient: focus on the severity of peripheral arterial disease. Ther Adv Endocrinol Metab 2013, 4:83-94.

10. Liu YS, Lu Y, Liu W, Xie H, Luo XH, Wu XP, Yuan LQ: Liao EY:Connective tissue growth factor is a down stream mediator for preptin-induced proliferation and differentiation in human osteoblasts. Amino Acids 2010, 38:763-769.

11. Yuan LQ, Zhu JH, Wang HW, Liang QH, Xie H, Wu XP, Zhou H, Cui RR, Sheng ZF, Zhou HD, Zhu X, Liu GY, Liu YS, Liao EY: RANKL is a downstream mediator for insulin-induced osteoblastic differentiation of vascular smooth muscle cells. PLoS One 2011, 6:e29037.

12. Massy ZA, Drüeke TB: Vascular calcification. Curr Opin Nephrol Hypertens 2013, 22:405-412.

13. Ciceri P, Volpi E, Brenna I, Arnaboldi L, Neri L, Brancaccio D, Cozzolino M: Combined effects of ascorbic acid and phosphate on rat VSMC osteoblastic differentiation. Nephrol Dial Transplant 2012, 27:122-127.

14. Zhan JK, Wang YJ, Wang Y, Wang S, Tan P, Huang W, Liu YS: The mammalian target of rapamycin signalling pathway is involved in osteoblastic differentiation of vascular smooth muscle cells. Can J Cardiol 2014, 30:568-575.

15. Zhan JK, Wang YJ, Wang Y, Tang ZY, Tan P, Huang W, Liu YS: Adiponectin attenuates the osteoblastic differentiation of vascular smooth muscle cells through the AMPK/mTOR pathway. Exp Cell Res 2014, 323:352-358

16. Kaden JJ, Bickelhaupt S, Grobholz R, Vahl CF, Hagl S, Brueckmann M, Haase KK, Dempfle CE, Borggrefe M: Expression of bone sialoprotein and bone morphogenetic protein-2 in calcific aortic stenosis. J Heart Valve Dis 2004, 13:560-566.

17. Steitz SA, Speer MY, Curinga G, Yang HY, Haynes P, Aebersold R, Schinke T, Karsenty G, Giachelli CM: Smooth muscle cell phenotypic transition associated with calcification upregulation of $\mathrm{cbfa} 1$ and downregulation of smooth muscle lineage markers. Circ Res 2001, 89:1147-1154.

18. Liu H, Lu Q, Huang K: Selenium suppressed hydrogen peroxide-induced vascular smooth muscle cells calcification through inhibiting oxidative stress and ERK activation. J Cell Biochem 2010, 111:1556-1564.

19. Sattler AM, Schoppet M, Schaefer JR, Hofbauer LC: Novel aspects on RANK ligand and osteoprotegerin in osteoporosis and vascular disease. Calcif Tissue Int 2004, 74:103-106.

20. Bucay N, Sarosi I, Dunstan CR, Morony S, Tarpley J, Capparelli C, Scully S, Tan HL, Xu W, Lacey DL, Boyle WJ, Simonet WS: Osteoprotegerin-deficient mice develop early onset osteoporosis and arterial calcification. Genes Dev 1998, 12:1260-1268.

21. Min H, Morony S, Sarosi I, Dunstan CR, Capparelli C, Scully S, Van G, Kaufman S, Kostenuik PJ, Lacey DL, Boyle WJ, Simonet WS: Osteoprotegerin reverses osteoporosis by inhibiting endosteal osteoclasts and prevents vascular calcification by blocking a process resembling osteoclastogenesis. J Exp Med 2000, 192:463-474.

22. Panizo S, Cardus A, Encinas M, Parisi E, Valcheva P, López-Ongil S, Coll B, Fernandez E, Valdivielso JM: RANKL increases vascular smooth muscle cell calcification through a RANK-BMP4-dependent pathway. Circ Res 2009, 104:1041-1048.

23. Aoki A, Murata M, Asano T, Ikoma A, Sasaki M, Saito T, Otani T, Jinbo $\mathrm{S}$, Ikeda N, Kawakami M, Ishikawa SE: Association of serum osteoprotegerin with vascular calcification in patients with type 2 diabetes. Cardiovasc Diabetol 2013, 12:11.

24. Volpato S, Ferrucci L, Secchiero P, Corallini F, Zuliani G, Fellin R, Guralnik JM, Bandinelli S, Zauli G: Association of tumor necrosis factor-related 
apoptosis-inducing ligand with total and cardiovascular mortality in older adults. Atherosclerosis 2011, 215:452-458.

25. Shan PF, Lu Y, Cui RR, Jiang Y, Yuan LQ, Liao EY: Apelin attenuates the osteoblastic differentiation of vascular smooth muscle cells. PLoS One 2011, 6:e17938.

26. Liao XB, Zhou XM, Li JM, Yang JF, Tan ZP, Hu ZW, Liu W, Lu Y, Yuan LQ: Taurine inhibits osteoblastic differentiation of vascular smooth muscle cells via the ERK pathway. Amino Acids 2008, 34:525-530.

27. Shi Y, Tohyama Y, Kadono T, He J, Miah SM, Hazama R, Tanaka C, Tohyama K, Yamamura H: Protein-tyrosine kinase Sykis required for pathogen engulfment in complement-mediated phagocytosis. Blood 2006, 107:4554-4562.

28. Callegari A, Coons ML, Ricks JL, Rosenfeld ME, Scatena M: Increased Calcification in Osteoprotegerin-Deficient Smooth Muscle Cells: Dependence on Receptor Activator of NF-KB Ligand and Interleukin 6. J Vasc Res 2014, 51:118-131.

29. Mai QG, Zhang ZM, Xu S, Lu M, Zhou RP, Zhao L, Jia CH, Wen ZH, Jin DD, Bai XC: Metformin stimulates osteoprotegerin and reduces RANKL expression in osteoblasts and ovariectomized rats. J Cell Biochem 2011, 112:2902-2909.

30. Lee SK, Kalinowski J, Jastrzebski S, Lorenzo JA: 1,25(OH)2 vitamin D3-stimulated osteoclast formation in spleen-osteoblast cocultures is mediated in part by enhanced IL-1 alpha and receptor activator of NF-kappa B ligand production in osteoblasts. J Immunol 2002, 169:2374-2380

31. Kahn SE: The relative contributions of insulin resistance and beta-cell dysfunction to the pathophysiology of Type 2 diabetes. Diabetologia 2003, 46:3-19.

32. Xu W, Bi Y, Sun Z, Li J, Guo L, Yang T, Wu G, Shi L, Feng Z, Qiu L, Li Q, Guo X, Luo Z, Lu J, Shan Z, Yang W, Ji Q, Yan L, Li H, Yu X, Li S, Zhou Z, Lv X, Liang Z, Lin $S$, Zeng L, Yan J, Ji L, Weng J: Comparison of the effects on glycaemic control and $\beta$-cell function in newly diagnosed type 2 diabetes patients of treatment with exenatide, insulin or pioglitazone: a multicentre randomized parallel-group trial (the CONFIDENCE study). J Intern Med 2014, doi: 10.1111/joim.12293.

33. Bounthavong M, Tran JN, Golshan S, Piland NF, Morello CM, Blickensderfer A, Best JH: Retrospective cohort study evaluating exenatide twice daily and long-acting insulin analogs in a Veterans Health Administration population with type 2 diabetes. Diabetes Metab 2014, 40:284-291.

34. Kelly AS, Bergenstal RM, Gonzalez-Campoy JM, Katz H, Bank AJ: Effects of exenatide vs metformin on endothelial function in obese patients with pre-diabetes: a randomized trial. Cardiovasc Diabetol 2012, 11:64

35. Vergès $B$, Bonnard $C$, Renard E: Beyond glucose lowering: glucagon-like peptide-1 receptor agonists, body weight and the cardiovascular system. Diabetes Metab 2011, 37:477-488.

36. Bose AK, Mocanu MM, Carr RD, Brand CL, Yellon DM: Glucagon-like peptide 1 can directly protect the heart against ischemia/reperfusion injury. Diabetes 2005, 54:146-151.

37. Arakawa M, Mita T, Azuma K, Ebato C, Goto H, Nomiyama T, Fujitani Y, Hirose T, Kawamori R, Watada H: Inhibition of monocyte adhesion to endothelial cells and attenuation of atherosclerotic lesion by a glucagonlike peptide-1 receptor agonist, exendin-4. Diabetes 2010, 59:1030-1037

38. Bao W, Holt L, Prince RD, Jones GX, Aravindhan K, Szapacs M, Barbour AM, Jolivette LJ, Lepore JJ, Willette RN, DeAngelis E, Jucker BM: Novel fusion of GLP-1 with a domain antibody to serum albumin prolongs protection against myocardial ischemia/reperfusion injury in the rat. Cardiovasc Diabetol 2013, 12:148.

39. Ndip A, Williams A, Jude EB, Serracino-Inglott F, Richardson S, Smyth JV, Boulton AJ, Alexander MY: The RANKL/RANK/OPG signaling pathway mediates medial arterial calcification in diabetic Charcot neuroarthropathy. Diabetes 2011, 60:2187-2196.

40. Osako MK, Nakagami H, Shimamura M, Koriyama H, Nakagami F, Shimizu H, Miyake T, Yoshizumi M, Rakugi H, Morishita R: Cross-talk of receptor activator of nuclear factor-kB ligand signaling with renin-angiotensin system in vascular calcification. Arterioscler Thromb Vasc Biol 2013, 33:1287-1296.
41. Mazière C, Salle V, Gomila C, Mazière JC: Oxidized low density lipoprotein enhanced RANKL expression in human osteoblast-like cells. Involvement of ERK, NFkappaB and NFAT. Biochim Biophys Acta 2013, 1832:1756-1764.

42. Hochrainer K, Racchumia G, Anrather J: Hypo-phosphorylation leads to nuclear retention of NF-KB p65 due to impaired IkBa gene synthesis. FEBS Lett 2007, 581:5493-5499.

doi:10.1186/s12933-014-0153-4

Cite this article as: Zhan et al:: Exenatide can inhibit calcification of human VSMCs through the NF-kappaB/RANKL signaling pathway. Cardiovascular Diabetology 2014 13:153.

\section{Submit your next manuscript to BioMed Central and take full advantage of:}

- Convenient online submission

- Thorough peer review

- No space constraints or color figure charges

- Immediate publication on acceptance

- Inclusion in PubMed, CAS, Scopus and Google Scholar

- Research which is freely available for redistribution 